\title{
Trichodermodysplasia-dental alterations syndrome
}

INSERM

\section{Source}

INSERM. (1999). Orphanet: an online rare disease and orphan drug data base.

Trichodermodysplasia-dental alterations syndrome. ORPHA:3353

Trichodermodysplasia-dental alterations syndrome is a rare, genetic ectodermal

dysplasia syndrome characterized by sparse, thin, brittle scalp hair, as well as sparse eyebrows, eyelashes, axillary and pubic hair, delayed eruption of deciduous teeth and hypodontia of both dentitions. Mild palmoplantar keratosis, café-au-lait spots on back, mild dystrophy of nails, and tibial deflection of toes are also associated. There have been no further descriptions in the literature since 1986. 